Original Research Article

\title{
Chronopharmacology and drug prescribing pattern of physicians in a tertiary care hospital of North India
}

\author{
Diwanshu Sharma*, Pavan Malhotra
}

Department of Pharmacology, Acharya Shri Chander College of Medical Sciences and Hospital, Sidhra, Jammu, Jammu and Kashmir, India

Received: 21 December 2017

Revised: 02 January 2018

Accepted: 29 January 2018

\section{*Correspondence to:}

Dr. Diwanshu Sharma, Email: diwanshusharma2007@ gmail.com

Copyright: (C) the author(s), publisher and licensee Medip Academy. This is an openaccess article distributed under the terms of the Creative Commons Attribution NonCommercial License, which permits unrestricted noncommercial use, distribution, and reproduction in any medium, provided the original work is properly cited.

\begin{abstract}
Background: Chronopharmacology is the science dealing with the optimization of drug effects and the minimization of adverse effects by timing medication in relation to the biological rhythm. This concept came into picture to make us understand about periodic and predictable changes in both desired effects and tolerance of medication Chronotherapeutics approach gives more accurate determination of the time when patients are at highest risk and in greatest need of therapy. This Chronopharmacological principle is used in the therapy of various diseases like cardiovascular diseases, allergy and many more. The objective of the study was to analyse whether chronopharmacological approach was being applied in clinical practice by comparing chronopharmacology of 4 drugs to their prescribing pattern by the physicians.

Methods: This was observational study where 700 prescriptions written by physicians were audited. To study all the drugs would have been tedious so four commonly used drugs were chosen that is, Proton pump inhibitors, statins, Beta blockers and subcutaneous Insulin.

Results: Results showed that chronopharmacological approach has been applied in the clinical field though physician didn't have clear concept about chronopharmacology and it is relation to the prescribing. Despite this, maximum physician prescribing pattern was comparable to the chronopharmacological data except in case of Proton pump inhibitors.

Conclusions: It is concluded that Chronotherapeutics approach gives more accurate determination of the time when patients are at highest risk and in greatest need of therapy. Nevertheless, this variation is only seldom considered by clinicians. If drugs are prescribed by following chronopharmacological approach it can prove beneficial to the patients as more of effectiveness of the drug and lesser side effects.
\end{abstract}

Keywords: Beta blocker, Chronopharmacolgy, Proton pump inhibitors, Prescribing pattern, Statins, Subcutaneous insulin

\section{INTRODUCTION}

Homoestasis, the concept that came into light during 20 century is being challenged by emerging concepts from the field of chronobiology-science of biological rhythms. The branch dealing with the pharmacologic aspects of chronobiology is termed Chronopharmacology which may be subdivided into chronotherapy, chronopharmacokinetics and Chronotoxity. ${ }^{1}$
Chronopharmacology is the science dealing with the optimization of drug effects and the minimization of adverse effects by timing medication in relation to the biological rhythm. ${ }^{2}$

Historically, it was early recognized that rhythmic physiology resulted in rhythmic disease symptoms. Hippocrates already noticed ca. $400 \mathrm{BC}$ that daytime sleepiness is indicative of disease, and night time 
sleeplessness can indicate pain and suffering. ${ }^{3}$ For over thirty years, it has been known that drug absorption and distribution is subjected to diurnal variation in rodents and humans. A twenty-four hour change in drug bioavailability has therefore been established for hundreds of drugs in rodents and humans. For example, acetaminophen or theophylline. ${ }^{4,5}$ show different pharmacokinetics in the morning compared to evening. These changes are the results of several time-dependent modifications of physiological and molecular aspects that influence drug absorption and distribution.

Keeping in mind the wide spectrum of circadian (patho-) physiology, it is logical that the pharmacodynamics and pharmacokinetics (PK/PD) of many drugs would be circadian, and therefore that drug efficacy and safety profiles would also vary with time of day. Nevertheless, this variation is only seldom considered by clinicians, drug developers, or regulators. However, two decades of intensive research have uncovered a wealth of information not only about basic mechanisms of circadian clocks, but also about how they interact with physiology and disease. Below, we tried to analyse that whether our physician have any idea about chronopharmacology and whether chronopharmacological approach is being translated into clinical practice and to what extent.

\section{METHODS}

It was a cross-sectional observational study. The study was completed in four months from March 2017-June 2017.

\section{Inclusion criteria}

700 Prescriptions which included any of the four group of medications (Proton pump inhibitors, Statins, Beta blockers and Insulin) were audited, from OPD of medicine, ASCOMS, Jammu, to assess drug prescribing pattern of the physician in relation to the chronopharmacology of the respective drugs.

\section{Exclusion criteria}

Prescriptions which didn't include any of the above drugs were excluded from the study.
Ethical clearance was taken prior starting with the research. The purpose of the study was explained to the physicians prior auditing their prescriptions.

The results were calculated in percentage form. Number of prescription that were in chronological pattern were calculated to check whether how far physician is prescribing the drugs by using chronological approach.

\section{RESULTS}

The study was completed in four months from March-June. When physicians were asked about chronopharmacology very few knew exactly about the term though all had some vague idea about it. The prescriptions were audited, and it was seen that physician didn't had much concept about chronopharmacological approach but depending upon their knowledge maximum physicians prescribed the drugs as was chronological beneficial except in case of Proton pump inhibitors. Chronopharmacologically maximum synthesis of cholesterol takes place at night hence to prescribe drugs like statin, that reduce level of cholesterol, will prove beneficial when prescribed at bedtime. Maximum physician prescribed statin at bed time only (99.9\%). As far as insulin was concerned in patients of type 2 diabetes, higher dose should be given in the morning than latter part of the day as glucose tolerance increases from morning to evening. ${ }^{2}$ It was seen that physicians gave higher dose of insulin in the morning than in the later part of the day but as far as prescribing of proton pump inhibitors were concerned all physicians prescribed them early morning before the breakfast (Table 1) but chronopharmacologically it has been stated that maximum production of acid occurs at night between 10pm-2 am hence it'l be beneficial to the patient when asked to take before dinner and still, if exacerbation of symptoms occur ,then the PPI (Proton pump inhibitors) should be given in two divided doses morning and night. Similarly, beta blockers were prescribed early morning that fits in the chronopharmacological concept that anti-hypertensive medication should be given keeping in mind that the blood pressure rises early morning. Blood pressure is characterized by a circadian rhythm, both in hypertensive and in normotensive subjects; this pattern is associated with lower B.P values during sleeping time and periods of minimal activity and higher B.P levels during wakefulness and mental and physical activity. ${ }^{6}$

Table 1: Assess how far chronological approach translated to clinical practice.

\begin{tabular}{|lllll|}
\hline Class of drugs & $\begin{array}{l}\text { If Chronopharmacological } \\
\text { approach applied, timing of } \\
\text { medication that is beneficial }\end{array}$ & $\begin{array}{l}\text { Correctly } \\
\text { prescribed }\end{array}$ & $\begin{array}{l}\text { Not according to } \\
\text { chronopharmacologica } \\
\text { I rhythm }\end{array}$ & $\begin{array}{l}\text { \% of chronologically } \\
\text { correct prescriptions }\end{array}$ \\
\hline $\begin{array}{l}\text { Proton pump } \\
\text { inhibitors }\end{array}$ & Before dinner & 10 & 690 & $1.4 \%$ \\
\hline Statins & At bed time & 699 & 1 & $99.9 \%$ \\
\hline Insulin & $\begin{array}{l}\text { Higher dose early morning } \\
\text { than other part of the day }\end{array}$ & 695 & 5 & $99.2 \%$ \\
\hline Beta blockers & Early morning & 690 & 10 & $98.5 \%$ \\
\hline
\end{tabular}


Therefore except for prescribing pattern of Proton pump inhibitors rest all the drugs were prescribed by physician as would be chronopharmacologically beneficial to the patient.

\section{DISCUSSION}

Here drug describing pattern of physicians in a tertiary care hospital of North India was compared to the chronopharmacological pattern in which various drugs should be prescribed so that patient gets maximum benefit and least side effects from the drug. In this study, four drugs were chosen. They were Proton pump inhibitors, Statins, Beta blockers and Insulin.

\section{Need for Chronopharmacotherapy}

Chronopharmacology is required to monitor therapy so as to limit the duration of therapy especially in cases where patients are already having compromised renal, cardiac and hepatic or any other function of the body. Any type of accumulation of drugs in these organs causes greater toxicity which may led to diminished function of the organ. Thus, the chronopharmacotherapy becomes a very important part of treatment of several diseases particularly those effecting targeted body parts. ${ }^{7}$ According to the 1996 American medical association review, more consideration of chronotherapy in clinical trials is highly welcomed by the whole medical community. The result of the survey showed that 75 percent of the doctors are in favour of patient's circadian or daily rhythm-oriented treatment. ${ }^{8}$ From the various studies, it is formed that many cardiovascular events including myocardial infarction, stroke and sudden death occur during the initial hours of morning activity between 6 A.M. and 12 noon. And this is much higher during this period than other timing during the day. Blood pressure shows a sharp peak in the early morning, importantly coinciding with the peak for cardiovascular events, and an extended through during the night. ${ }^{9}$ At the same time, heart rate increases in the late morning or early afternoon. ${ }^{10}$ Platelet aggregation is increased and fibrnolytic activity is deceased in the morning, leading to a state of relative hyper coagulability of the blood.

As far as acid production is concerned, it has been stated that maximum acid production occurs during night between $10 \mathrm{pm}$ to 2 am hence medication for acid peptic disease will be beneficial when given at night. Similarly, tolerance to glucose increases from morning to evening hence in patients of type 2 diabetes dose of insulin should be given in higher quantity compared to other part of the day. ${ }^{2}$ Chronopharmacologically maximum synthesis of cholesterol takes place at night hence to prescribe drugs like statin that reduce level of cholesterol will prove beneficial when prescribed at bedtime. In our study maximum physicians were prescribing the medication as chronopharmacologically it can benefit the patient but as far as PPIs (Proton pump inhibitors) were concerned physician prescribed them before breakfast instead of prescribing it at bed time. This shows that the chronopharmacological approach is yet to be enforced in the clinical practice.

\section{CONCLUSION}

The recent findings that we have highlighted all yield insight into the rising concept of chronopharmacology. Although there has been much more awareness of the impact of the circadian clock on health, disease, and treatment in recent years, these findings seem to not have translated into clinics or regulatory agencies on a broad scale.

\section{ACKNOWLEDGEMENTS}

Authors would like to sincerely thank faculty members of Medicine department for their co-operation for conduct of study. Also they are very grateful to all the patients for their co-operation during the study.

\section{Funding: No funding sources}

Conflict of interest: None declared

Ethical approval: The study was approved by the Institutional Ethics Committee

\section{REFERENCES}

1. Pandit V, Suresh S. Emerging role of biorhythms in optimizing treatment of disease. Indian $\mathbf{J}$ novel drug delivery. 2009;1;2-10.

2. Motghare VM, Faruqui AA, Dudhgaonkar S, Turankar AV. Cronopharmacology. In: SD Seth, Vimlesh Seth. Textbook of Pharmacology. $3^{\text {rd }}$ Edition. Elsevier India; 2009:XVI.7.

3. Hippocrates, Laurentianus L, Galen. Hippocratis medici Sententiarum particula prima[-septima] Antonius Miscominus ex archetypo Laurentii imprimi curauit; Florentiae: 1494:196.

4. Kamali F, Fry JR, Bell GD. Temporal variations in paracetamol absorption and metabolism in man. Xenobiotica; the fate of foreign compounds in biological systems. 1987;17:635-41.[PubMed]

5. Watanabe H, Nakano S, Nagai K, Ogawa N. TimeDependent Absorption of Theophylline in Man. Journal of Clinical Pharmacology. 1984;24:509-14. [PubMed]

6. Macchiarulo C, Pieri R, Mitolo DC, Pirrelli A. Management of anti-hypertensive treatment with lisinopril- a chronotherapeutics approach. European review for medical and pharmacological sciences. 1999;3:269-75.

7. Koppiseti VS, Sunalatha SH. Chronopharmacologly and chronopharmacotherapy-a guide to better health. Res J Pharma bio and chem. Sci. 2011;2:266-72.

8. Aodah AH. Design and evaluation of chronotherapeutics drug delivery system for the treatment of nocturnal asthma. King Saud university; 2009. 
9. Lago A, Geffner D, Tembl J, Landete L, Valero C, Baquero M. Circadian variation in acute ischemic stroke: a hospital-based study. Stroke; a journal of cerebral circulation. 1998;29:1873-5.[PubMed]

10. Smith David HG. Pharmacology of cardiovascular chronotherapeutics agents. AJH. 2001;14:296-301.
Cite this article as: Sharma D, Malhotra $P$. Chronopharmacology and drug prescribing pattern of physicians in a tertiary care hospital of North India. Int J Basic Clin Pharmacol 2018;7:499-502. 